\title{
$\$$ Research Square

\section{Effects of Modified Subxiphoid Thoracoscopic Surgery and Traditional Surgery On Pain Mediators and Pain Stress Levels in Patients With Anterior Mediastinal Teratoma}

\section{Panpan Zhang}

Jingmen First People's Hospital

Dan Liu

Wuhan First Hospital

Dong Luo

Wuhan First Hospital

Fuli Pang ( $\square$ 772449011@qq.com )

Taizhou First People's Hospital

\section{Research article}

Keywords: Thoracoscopy, Teratoma, Pain mediators, Stress level

Posted Date: September 22nd, 2021

DOl: https://doi.org/10.21203/rs.3.rs-910430/v1

License: () (1) This work is licensed under a Creative Commons Attribution 4.0 International License. Read Full License 


\section{Abstract \\ Background}

To investigate the effects of modified subxiphoid thoracoscopic surgery and traditional surgery on pain mediators and pain stress levels in patients with anterior mediastinal teratoma.

\section{Method}

Eighty patients with anterior mediastinal teratoma who underwent surgery in our hospital from May 2019 to May 2021 were selected as the subjects of this prospective study. According to the random residue grouping method, they were divided into a control group and observation group with 40 cases each. Among them, the control group underwent traditional surgery, and the observation group underwent modified subxiphoid thoracoscopic surgery. Observe and compare the surgical indicators, pain-causing mediators, and pain stress levels of the two groups of patients.

\section{Result}

The intraoperative blood loss, postoperative extubation time, and total drainage volume of the observation group were significantly lower than those of the control group, while the operation time was significantly higher than that of the control group, which was statistically significant $(P<0.05)$. There was no statistically significant difference in the pain-causing mediators of the two groups before surgery $(P>0.05)$, while the NPY, PGE2 and 5-HT at 1 day after surgery were significantly different, and the observation group was better than the control group. The comparison was statistically significant. Significance $(P<0.05)$. There was no statistically significant difference in pain stress levels between the two groups before surgery $(P>0.05)$, while NO, IL-6, and IL- $\beta 1$ day after surgery were significantly different, and the observation group was better than the control group. Statistically significant $(P<0.05)$.

\section{Conclusion}

The modified subxiphoid thoracoscopic surgery has a significant effect, reduces the level of peripheral blood pain-causing factors, relieves the pain of the patient, and promotes the recovery of the patient. It provides a certain reference for the mediastinal teratoma before the clinical operation.

\section{Background}

The mediastinum is the general term for the organs and tissues clamped on the inner side of the left and right pleural cavity. The front boundary of the mediastinum is the sternum, the back boundary is the thoracic vertebrae, the upper boundary is the junction of the thoracic entrance and the neck, and the lower boundary is the diaphragm. There are many tissues and organs in the mediastinum. The source of the organizational structure is complex [1]. There are many types of tumors. The anterior, middle, and posterior mediastinum is anatomically divided by the front and back of the pericardium. The tumors located in the anterior mediastinum 
are mostly thymoma, thymic cyst, and embryogenic tumors. Early anterior mediastinal tumors related to location, size, and whether it invades adjacent tissues or organs are mostly clinically without obvious symptoms. Most patients are found by physical examination. Some patients may have myasthenia gravis or go to the doctor for other reasons. When the tumor continues to grow and compress adjacent organs such as bronchus, lungs, and superior vena cava, breathing difficulties, hoarseness, pleural effusion, and palpitations may occur and superior vena cava obstruction syndrome and other clinical manifestations [2]. Anterior mediastinal teratoma is the first choice for chest CT in imaging diagnosis, which can clarify the positional relationship and boundary between the lesion and its surrounding tissues or organs. After enhanced scanning, it is difficult to determine the nature of the lesion before surgery based on clinical symptoms and imaging findings, which constitutes the complexity of clinical diagnosis and treatment. Mediastinal teratoma is one of the more common tumors in mediastinal tumors, with an incidence of approximately $21.5 \%$ of primary mediastinal tumors. With the clinical application of endoscopic surgery and endoscopic suture cutters, the birth of thoracoscopy with subxiphoid approach. Compared with traditional thoracotomy, subxiphoid thoracoscopy has the advantages of less trauma, less intraoperative blood loss, a clear surgical field, and quicker postoperative recovery. With the continuous development of modern minimally invasive surgical techniques and minimally invasive surgery In-depth creation of ideas [3]. Traditional surgical operations may damage and stretch the muscles and intercostal nerves during the operation. Postoperative pain is obvious, and movement and sensory disturbances are prone to occur. Traditional open surgery such as midline incision or lateral thoracic incision is more traumatic, and the postoperative hospital stay is long [4].

With the development of minimally invasive surgery, thoracoscopic surgery has gradually been applied to the clinical treatment of mediastinal teratoma. Therefore, traditional surgical incisions must pass through the intercostal space, and acute or chronic pain is prone to occur after surgery, which affects the patient's postoperative recovery [5]. In order to find a new surgical approach, it is a new idea to avoid injury caused by the intercostal approach. The subxiphoid thoracoscopic surgery completely avoids the intercostal incision, reduces postoperative pain, and promotes postoperative recovery of patients [6]. Subxiphoid thoracoscopic surgery can explore the bilateral thoracic cavity. Subxiphoid thoracoscopic surgery fully exposes the relationship between the anterior mediastinal tumor and the main large blood vessels in the mediastinum. In recent years, the thoracic cavity of the subxiphoid approach has been fully exposed. There are more and more reports of mediastinal tumor resection before microscope [7]. Based on this, our hospital has explored the effects of modified subxiphoid thoracoscopic surgery and traditional surgery on the pain mediators and pain stress levels of patients with anterior mediastinal teratoma. The current research results are reported as follows.

\section{Methods}

\section{General Information}

All records of patients' identities included in this study will be kept in hospitals as required, and public reports on the results of the study will not disclose all records of patients' identities. All patients had informed consent before being enrolled in the group, fully communicated with the patients before the experiment, introduced the content and process of the experiment, related risks, and possible adverse reactions, signed the informed consent form after obtaining the consent of the patients, and informed the patients of the test results in strict 
accordance with the experimental procedures. Eighty patients with anterior mediastinal teratoma who underwent surgery in our hospital from May 2019 to May 2021 were selected as the subjects of this prospective study. According to the random residue grouping method, they were divided into a control group and an observation group with 40 cases each. General data such as gender and age of the two groups of patients did not affect this test, as shown in Table 1.

\section{Inclusion and Exclusion criteria}

Inclusion criteria: $\llbracket$ All patients in this study met the "Chinese Expert Consensus on Chest Wall Tumor Resection and Chest Wall Reconstructive Surgery (2018 Edition)" [8] diagnostic criteria for anterior mediastinal

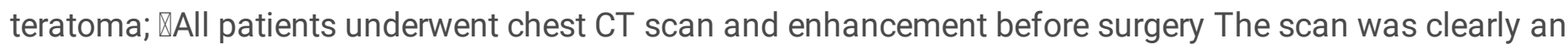
anterior mediastinal tumor. The tumor showed limited lesions and a clear boundary with surrounding tissues. It can be completely removed at one time. The diameter of the tumor is less than or equal to $5 \mathrm{~cm}$ and the relationship with the surrounding organs is clear. There is no obvious invasion with or without severe weakness; $\otimes$ The preoperative coagulation function, blood biochemistry, arterial blood gas, cardiac ejection fraction, lung function, etc. meet the surgical requirements, expected Can tolerate one-lung ventilation and general anesthesia. Exclusion criteria: $\triangle T$ The tumor diameter is greater than $5 \mathrm{~cm}$ and the relationship with the surrounding organs is clear, there is obvious invasion, with or without severe weakness, and previous pleural inflammation; $₫ T$ The general condition is poor and cannot tolerate one-lung ventilation; respiratory dysfunction FEV1 $<1 \mathrm{~L}$, patients with multiple organ dysfunction such as cardiac dysfunction ( $\geq$ grade 3 ), patients with coagulation dysfunction; $\$ poor general conditions, accompanied by severe heart, lung, liver, kidney and other important organs with severe organic disease, With a history of organic brain disease and a history of mental illness.

\section{Methodology}

Among them, the control group underwent traditional surgical procedures, that is, patients were given general anesthesia, double-lumen endotracheal intubation, single-lung ventilation, $30^{\circ}$ lateral decubitus position, suspension of the upper limbs; incision length $\sim 1 \mathrm{~cm}$ at the anterior axillary line at the fifth intercostal position $2 \mathrm{~cm}$ is used as a mirror hole, and a $2 \sim 3 \mathrm{~cm}$ incision is made at the midline of the ischial at the $3 \mathrm{rd}$ intercostal or 5 th intercostal position as an operating hole, carbon dioxide $\left(\mathrm{CO}_{2}\right)$ is filled in to create an artificial pneumothorax, and the position of the incision is adjusted appropriately according to the position of the tumor; Take the right approach as an example. Take an electric hook through the lower pole of the thymus and dissociate with an ultrasonic knife. At the same time, open the mediastinal pleura at the surface of the pericardium, and then move upwards along the phrenic nerve and the internal mammary artery to the superior vena cava and the internal mammary artery. At the junction, free to the thymus arteries and veins, take the titanium clip to clamp the severance, and remove the thymus, and then completely stop the bleeding, place a closed drainage tube, and suture layer by layer.

The observation group performed a modified subxiphoid thoracoscopic surgery, that is, the patient was placed in a supine position, and after successful single-lumen endotracheal intubation anesthesia, the upper abdomen and chest were sterilized and spread. Take the midline of the rectus abdominis under the xiphoid process and cut the skin $2 \mathrm{~cm}$ longitudinally as the observation hole. The surgeon uses his fingers to close the xiphoid process and bluntly separates the posterior sternal space upwards. Insert a $5 \mathrm{~mm}$ Trocar into a $0.5 \mathrm{~cm}$ incision, 
insert a grasping forceps and an ultrasonic knife, insert a $10 \mathrm{~mm}$ Trocar into the observation hole, put a $30^{\circ}$ thoracoscope into the observation hole, continue to inject $\mathrm{CO}_{2}$, maintain a pressure of $8-10 \mathrm{mmHg}$, and push away the double Lateral lung tissue, revealing the innominate vein, the tissue between the phrenic nerve and the pericardium. Cut the mediastinal pleura with an ultrasonic knife, and remove the side of the pericardium, above the diaphragm, and between the bilateral phrenic nerve and the innominate vein from bottom to top along the mediastinal pleura. The anterior mediastinal adipose tissue in the area carefully identifies and protects the superior vena cava, innominate vein, and phrenic nerve. The thymic vein was cut off, and then a total thymectomy was performed, and then the specimen was taken out. After the operation, a drainage tube was placed in the observation hole and the wound was sutured. Both groups were given anti-infective treatment. see image 1.

\section{Follow-up and observation indicators}

The levels of neuropeptide Y (NPY), 5-hydroxytryptamine (5-HT), and other pain-causing factors in the peripheral blood of the two groups of patients before and on the first day after surgery, peripheral blood nitric oxide (NO) and interleukin- $\beta$ (IL- $\beta$ ), interleukin- 6 (IL-6) and other pain stress index levels; enzyme-linked immunosorbent assay (ELISA) was used to detect the levels of NPY, PGE2, $5-\mathrm{HT}$, IL-6, IL- $\beta$, The nitrate reductase method was used to detect the level of NO, and the visual analog scoring method was used to evaluate postoperative pain.

\section{Statistical Analysis}

All statistical data in this study were entered into the excel software by the first author and the corresponding author respectively. The included data were tested by the Shapiro-Wilk method. The measurement data that conformed to the normal distribution were described by the mean \pm standard deviation ( $\overline{\mathrm{x}} \pm S$ ), and between groups or the independent sample or paired-sample t-test was performed within the group, and the count data were described in integers or percentages (\%), and the $\chi^{2}$ test was used between or within groups. The included data that do not conform to the normal distribution is described by $M(Q R)$, using Mann-Whitney-test, and the test level is $a=0.05$.

\section{Results}

\section{Comparison of general information}

The general data of the two groups of patients, such as gender, average age, lesion diameter, body mass index, and comorbidities, were not significantly different after the $t$-test and chi-square test $(P>0.05)$. See Table 1 . 
Table 1

Comparison of general information between the two groups $(\mathrm{n}, \overline{\mathrm{x}} \pm \mathrm{s})$

\begin{tabular}{|c|c|c|c|c|c|c|c|}
\hline \multirow[t]{2}{*}{ Group } & \multirow{2}{*}{$\begin{array}{l}\text { Gender } \\
\text { (men/ } \\
\text { women) }\end{array}$} & \multirow{2}{*}{$\begin{array}{l}\text { Average } \\
\text { age } \\
\text { (yrs.) }\end{array}$} & \multirow{2}{*}{$\begin{array}{l}\text { Lesion } \\
\text { diameter } \\
\text { (cm) }\end{array}$} & \multirow{2}{*}{$\begin{array}{l}\text { Body } \\
\text { mass } \\
\text { index } \\
\left(\mathrm{kg} / \mathrm{m}^{2}\right)\end{array}$} & \multicolumn{3}{|l|}{ Complications } \\
\hline & & & & & Hypertension & Diabetes & Hyperlipidemia \\
\hline $\begin{array}{l}\text { Control } \\
\text { group (40) }\end{array}$ & $18 / 22$ & $\begin{array}{l}49.78 \pm \\
4.32\end{array}$ & $\begin{array}{l}4.66(3.17 \\
\sim 7.09)\end{array}$ & $\begin{array}{l}27.78 \pm \\
2.32\end{array}$ & 18 & 16 & 6 \\
\hline $\begin{array}{l}\text { Observation } \\
\text { group }(40)\end{array}$ & $17 / 23$ & $\begin{array}{l}51.62 \pm \\
4.66\end{array}$ & $\begin{array}{l}4.59(3.31 \\
\sim 7.72)\end{array}$ & $\begin{array}{l}27.62 \pm \\
2.66\end{array}$ & 17 & 18 & 5 \\
\hline$\chi^{2} / t / z$ & 0.051 & -1.831 & 0.040 & 0.020 & 0.237 & & \\
\hline$P$ & 0.822 & 0.071 & 0.965 & 0.984 & 0.888 & & \\
\hline
\end{tabular}

\section{Comparison Of Surgical Indicators}

In the Observation group patients, intraoperative blood loss, postoperative extubation time, and total drainage were significantly lower than those of the Control group, while the operation time was significantly higher than that of the Control group, which was statistically significant $(P<0.05)$. See Table 2.

Table 2

Comparison of surgical indicators between the two groups $(\overline{\mathrm{x}} \pm \mathrm{s})$

\begin{tabular}{|lllll|}
\hline Group & $\begin{array}{l}\text { Intraoperative blood } \\
\text { loss }(\mathrm{ml})\end{array}$ & $\begin{array}{l}\text { Operation time } \\
(\mathrm{min})\end{array}$ & $\begin{array}{l}\text { Postoperative extubation } \\
\text { time (d) }\end{array}$ & $\begin{array}{l}\text { Total } \\
\text { drainage (ml) }\end{array}$ \\
\hline $\begin{array}{l}\text { Control } \\
\text { group(40) }\end{array}$ & $58.34 \pm 3.18$ & $129.78 \pm 18.32$ & $4.34 \pm 1.30$ & $\begin{array}{l}414.51 \pm \\
27.82\end{array}$ \\
\hline $\begin{array}{l}\text { Observation } \\
\text { group(40) }\end{array}$ & $55.32 \pm 5.63$ & $148.62 \pm 21.66$ & $3.36 \pm 1.06$ & \begin{tabular}{l}
$312.87 \pm$ \\
\hline$t$
\end{tabular} \\
\hline$P$ & 2.954 & -4.200 & 3.695 & 21.270 \\
\hline$P$ & 0.004 & 0.000 & 0.000 & 0.000 \\
\hline
\end{tabular}

\section{Comparison Of Pain-causing Agents}

There was no statistically significant difference in the preoperative pain-causing agents between the two groups of patients $(P>0.05)$, while the comparison of NPY, PGE2, and 5-HT on the first day after surgery was significantly different, and the Observation group was better than the Control group. The comparison was statistically significant. Significance $(P<0.05)$. See Table 3. 
Table 3

Comparison of pain mediators between the two groups $(\overline{\mathrm{x}} \pm \mathrm{s})$

\begin{tabular}{|c|c|c|c|c|c|c|}
\hline \multirow[t]{2}{*}{ Group } & \multicolumn{2}{|l|}{ NPY( $(\mathbb{g} / \mathrm{L})$} & \multicolumn{2}{|l|}{ PGE2(pg/ml) } & \multicolumn{2}{|l|}{ 5-HT(ng/L) } \\
\hline & Preoperative & $\begin{array}{l}1 \text { day after } \\
\text { surgery }\end{array}$ & Preoperative & $\begin{array}{l}1 \text { day after } \\
\text { surgery }\end{array}$ & Preoperative & $\begin{array}{l}1 \text { day } \\
\text { after } \\
\text { surgery }\end{array}$ \\
\hline $\begin{array}{l}\text { Control } \\
\text { group(40) }\end{array}$ & $\begin{array}{l}182.78 \pm \\
20.32\end{array}$ & $\begin{array}{l}243.34 \pm \\
21.40\end{array}$ & $\begin{array}{l}138.51 \pm \\
8.32\end{array}$ & $\begin{array}{l}252.78 \pm \\
20.32\end{array}$ & $\begin{array}{l}156.94 \pm \\
23.40\end{array}$ & $\begin{array}{l}224.67 \\
\pm 28.12\end{array}$ \\
\hline $\begin{array}{l}\text { Observation } \\
\text { group }(40)\end{array}$ & $\begin{array}{l}184.62 \pm \\
20.66\end{array}$ & $\begin{array}{l}204.76 \pm \\
21.64\end{array}$ & $\begin{array}{l}139.55 \pm \\
8.11\end{array}$ & $\begin{array}{l}203.62 \pm \\
23.66\end{array}$ & $\begin{array}{l}155.96 \pm \\
19.24\end{array}$ & $\begin{array}{l}186.49 \\
\pm 31.37\end{array}$ \\
\hline$t$ & -0.402 & 8.017 & -0.566 & -9.969 & 0.205 & 5.731 \\
\hline$P$ & 0.689 & 0.000 & 0.573 & 0.000 & 0.838 & 0.000 \\
\hline
\end{tabular}

\section{Comparison Of Pain Stress Levels}

There was no statistically significant difference between the two groups of patients in the preoperative pain stress level $(P>0.05)$, while the NO, IL-6, and IL- $\beta 1$ day after the operation was significantly different, and the Observation group was better than the Control group. Academic significance $(P<0.05)$. See Table 4.

Table 4

Comparison of pain stress levels between the two groups $(\overline{\mathrm{x}} \pm \mathrm{s})$

\begin{tabular}{|c|c|c|c|c|c|c|}
\hline \multirow[t]{2}{*}{ Group } & \multicolumn{2}{|l|}{$\mathrm{NO}(\llbracket \mathrm{mol} / \mathrm{ml})$} & \multicolumn{2}{|l|}{ IL-6(pg/ml) } & \multicolumn{2}{|l|}{$\mathrm{IL}-\beta(p g / m \mathrm{l})$} \\
\hline & Preoperative & $\begin{array}{l}1 \text { day after } \\
\text { surgery }\end{array}$ & Preoperative & $\begin{array}{l}1 \text { day after } \\
\text { surgery }\end{array}$ & Preoperative & $\begin{array}{l}1 \text { day } \\
\text { after } \\
\text { surgery }\end{array}$ \\
\hline $\begin{array}{l}\text { Control } \\
\text { group(40) }\end{array}$ & $\begin{array}{l}126.34 \pm \\
13.18\end{array}$ & $\begin{array}{l}195.78 \pm \\
13.32\end{array}$ & $6.28 \pm 0.80$ & $\begin{array}{l}11.81 \pm \\
1.39\end{array}$ & $1.93 \pm 0.27$ & $\begin{array}{l}2.75 \pm \\
0.44\end{array}$ \\
\hline $\begin{array}{l}\text { Observation } \\
\text { group }(40)\end{array}$ & $\begin{array}{l}126.32 \pm \\
15.63\end{array}$ & $\begin{array}{l}158.62 \pm \\
19.66\end{array}$ & $6.19 \pm 0.74$ & $8.41 \pm 0.31$ & $1.74 \pm 0.23$ & $\begin{array}{l}3.37 \pm \\
0.37\end{array}$ \\
\hline$t$ & 0.006 & 9.897 & 0.522 & 15.099 & 3.388 & -6.821 \\
\hline$P$ & 0.995 & 0.000 & 0.603 & 0.000 & 0.001 & 0.000 \\
\hline
\end{tabular}

\section{Discussion}

Mediastinal teratoma is an embryogenic tumor, which usually occurs in young adults. There is no significant difference in incidence between men and women, and benign is common [9]. Surgery is the key to the treatment of mediastinal teratoma. The surgical approaches for mediastinal teratoma include median sternum split, transthoracic intercostal incision, and subxiphoid incision. With the development of endoscopic technology and the advancement of medical instruments, thoracic cavity Microscopic techniques are also used 
in mediastinal teratoma surgery [10]. The median sternum split is still the gold standard for anterior mediastinal teratoma resection, especially for patients with huge anterior mediastinal teratoma. The median sternotomy approach is well exposed, and the operation is relatively simple and safe. It can maximize the protection of bilateral phrenic nerves, pericardial phrenic vessels, innominate veins, etc. When the tumor is large and involves surrounding important organs or blood vessels, it is convenient to operate [11]. The disadvantage is that the surgical incision is long, the trauma is large, and the integrity of the thoracic cage is destroyed, the postoperative hospital stay is long, the recovery time is long, and it is difficult to be accepted by the patient [12].

In recent years, there have been more and more reports on the treatment of thoracic diseases with subxiphoid thoracoscopic surgery. Compared with traditional lateral thoracic thoracoscopic surgery, the advantages of thoracoscopic surgery through the subxiphoid approach are: The incision will not cause damage to the intercostal muscles and nerves, and can minimize pain. The use of painkillers after surgery is shortened, which helps patients recover quickly after surgery [13]. The surgical field of view of the inferior xiphoid approach can well expose the anterior mediastinum and fully reveal the boundaries between the tumor and the innominate vein and the superior vena cava. After opening the bilateral mediastinal pleura, a visual field similar to that of the median thoracot can be obtained. If the thymus is enlarged, The thymus, phrenic nerve, and its adjacent tissue spaces can be fully exposed during the operation, so that the thymus, anterior mediastinal fat, and pericardial fat tissue can be completely removed [14]. The lateral thoracic approach is only a unilateral thoracic operation, and the contralateral thoracic cavity cannot be explored. Subxiphoid thoracoscopic surgery can explore the bilateral thoracic cavity [15]. It can treat bilateral lesions at the same time and is especially suitable for patients with anterior mediastinum and bilateral lung lesions, such as bilateral pulmonary bullae or double lung metastases and anterior mediastinal lesions [16]. However, the disadvantage of the subxiphoid approach is the narrow operation space behind the sternum, and the lengthened endoscopic instruments required for the subxiphoid thoracoscopic surgery require the surgeon to operate more technically, and the corresponding surgical risk will also increase [16]. This requires the surgeon to have rich experience in thoracoscopic surgery and be very familiar with its structure and the relationship between adjacent tissues. In addition, the subxiphoid approach is more difficult for the operation of the pleura and the apex of the lung. If large bleeding occurs, it is more difficult to stop the bleeding. When performing the left thoracic operation in the subxiphoid thoracoscopic surgery, endoscopic instruments are used during the operation. Compression or stimulation of the heart may cause complications such as intraoperative and postoperative arrhythmia [17].

This study showed that the intraoperative blood loss, postoperative extubation time, and total drainage volume of the observation group were significantly lower than those of the control group, while the operation time was significantly higher than that of the control group. NPY, PGE2, 5- The difference in HT was obvious and the observation group was better than the control group. There was no statistically significant difference in the pain stress level of the two groups before surgery. One day after the operation, the differences in NO, IL-6, and IL- $\beta$ were significant, and the observation group was better than the control group, which was statistically significant. It shows that the modified subxiphoid thoracoscopic surgery has a significant effect, reduces the level of peripheral blood pain-causing factors, relieves the pain of the patient, and promotes the recovery of the patient. The innovation of this study is that it can significantly improve the anterior mediastinum surgical field. The panoramic view reveals the left and right innominate veins, the upper phrenic nerve, and the anterior wall of the trachea, and the surgical field similar to the median sternotomy can be obtained [18]. Significantly increase the operating space of the anterior mediastinal surgery area, reduce the risk of accidental injury during 
the operation, and eliminate the need for excessive intrathoracic $\mathrm{CO}_{2}$ positive pressure, which can avoid the risks of intraoperative hypoxemia and air embolism, and effectively reduce the risk of intraoperative anesthesia management [19]. During the operation, the patient is in the supine position. If there is bleeding during the operation, they can be quickly transferred to the central thoracotomy. Because the posterior sternal space has been separated previously, the time of the transfer thoracotomy can be significantly shortened, and the safety of the operation is greatly improved [20]. Surgical trauma can promote the production of inflammatory factors such as NO, IL-6, IL- $\beta$, and other inflammatory factors, which can increase the activity of phospholipase A2 through $\mathrm{G}$ protein-coupled receptors, and promote the production of prostaglandins and arachidonic acid. Prostaglandin E (PGE2) is an important pain-causing factor caused by surgical trauma. PGE2 can not only directly affect the surrounding nociceptors, but also promote the transmission of pain in the spinal cord [21]. Studies have shown that PGE2 has strong physiological activity and can induce inflammatory reactions, increase local capillary permeability, and cause local swelling and pain. PGE2 can directly cause pain or increase nerve root sensitivity, reduce nerve root pain threshold, and increase pain sensation [22]. It can cause tissue edema, vasospasm, and platelet release, and promote the production and release of 5-HT. In terms of pain regulation, 5-HT has duality. 5-HT has an analgesic effect in the center and an analgesic effect in the periphery [23]. In the periphery, 5-HT can activate adrenergic beta receptors, promote the release of prostaglandins, excite sympathetic nerve receptors, increase the level of amines, and cause pain. NPY can affect the $\mathrm{Ca}^{2+}$ of the postsynaptic membrane, promote cell membrane depolarization, or promote vasoconstriction through the renin-angiotensin system, triggering a strong spasm of small blood vessels and causing pain [24].

\section{Conclusion}

Though this study is novel to some extent, it also has shortcomings. It explores the clinical effects of modified subxiphoid thoracoscopic surgery and traditional surgery on patients with anterior mediastinal teratoma, but the specific mechanism has not been studied for a long time. The collected cases came from the same hospital and were poorly represented. Both exclusion and inclusion are subjective, which may lead to biased results. In summary, the modified subxiphoid thoracoscopic surgery has a significant effect, reduces the level of peripheral blood pain-causing factors, relieves the pain of the patient, and promotes the recovery of the patient, which provides a certain reference for the mediastinal teratoma before the clinical operation.

\section{List Of Abbreviations}

NPY- neuropeptide Y

PGE2- Prostaglandin E

5-HT - 5-hydroxytryptamine

NO- Nitric oxide

IL- $\boldsymbol{\beta}$ - Interleukin- $\beta$,

IL-6- Interleukin-6 
ELISA- Enzyme-linked Immunosorbent Assay

\section{Declarations}

\section{Ethics approval and consent to participate}

All patients were informed and signed the consent before being enrolled in the group.

\section{Consent for publication}

Not applicable

\section{Availability of data and materials}

The datasets used and/or analysed during the current study are available from the corresponding author on reasonable request.

\section{Competing interests}

The authors declare that they have no competing interests

\section{Funding}

Not applicable

\section{Authors' contributions}

PZ, DL collected, Investigated, interpreted the data. PZ, DL, and DL contributed in writing and reviewing the manuscript. FP generated the idea, and revised and edited the manuscript. All authors read and approved the final manuscript

\section{Acknowledgements}

Not applicable

\section{Authors' information}

Affiliations

\section{Panpan Zhang}

Department of Cardiothoracic Surgery, Jingmen First People's Hospital, Hubei Province, China- 448000.

\section{Dan Liu}

Thoracic Surgery Department, Wuhan First Hospital, Hubei province, China -430000 .

\section{Dong Luo}


Thoracic Surgery Department, Wuhan First Hospital, Hubei province, China- 430000.

Fuli Pang (Corresponding Author)

Department of Emergency, Taizhou First Peoples Hospital, Zhejiang, China- 318020.

Email:772449011@qq.com,

\section{References}

1. Mouchová Z, Rosová B, Matěj R. Frozen section of lung, pleura and mediastinum specimen: Retrospective analysis of 5-years practical experiences and review of the literature. Cesk Patol. 2018;54(3):127-31.

2. Benveniste MF, Gomez D, Carter BW, et al. Radiation Effects in the Mediastinum and Surroundings: Imaging Findings and Complications. Semin Ultrasound CT MR. 2016;37(3):268-80. doi:10.1053/j.sult.2015.11.002.

3. Manson DE. Magnetic resonance imaging of the mediastinum, chest wall and pleura in children. Pediatr Radiol. 2016;46(6):902-15. doi:10.1007/s00247-016-3598-7.

4. Wu J, Shangguan $\mathrm{H}$, Zhou S, et al. Hemolymphangioma in the posterior mediastinum: a case report and literature review. Clin Respir J. 2018;12(1):302-5. doi:10.1111/crj.12474.

5. Nguyen GT, Ngoc Nguyen T, Duc Vu T, et al. Nonanemic extramedullary hematopoiesis in the posterior mediastinum. Asian Cardiovasc Thorac Ann. 2019;27(2):135-7. doi:10.1177/0218492318818966.

6. Czarnecka K, Yasufuku K. The role of endobronchial ultrasound/esophageal ultrasound for evaluation of the mediastinum in lung cancer. Expert Rev Respir Med. 2014;8(6):763-76.

doi:10.1586/17476348.2014.985210.

7. Carter BW, Benveniste MF, Madan R, et al. ITMIG Classification of Mediastinal Compartments and Multidisciplinary Approach to Mediastinal Masses. Radiographics. 2017;37(2):413-36. doi:10.1148/rg.2017160095.

8. Lei W, Jing L, Daixing Z. Chinese Expert Consensus on Chest Wall Tumor Resection and Chest Wall Reconstructive Surgery. Chinese J Clin Thorac Cardiovasc Surg. 2019;26(1):7-13.

9. Lehane A, Fatula L, Ben-Or S, et al. Resection of Mediastinal Teratoma Invading the Lung and Pericardium. Am Surg. 2020,3134820923298. doi:10.1177/0003134820923298.

10. Tian Z, Liu H, Li S, et al. Surgical treatment of benign mediastinal teratoma: summary of experience of 108 cases. J Cardiothorac Surg. 2020;15(1):36. doi:10.1186/s13019-020-1075-8.

11. Le Fèvre C, Vigneron $\mathrm{C}$, Schuster $\mathrm{H}$, et al. Metastatic mediastinal mature teratoma with malignant transformation in a young man with an adenocarcinoma in a Klinefelter's syndrome: Case report and review of the literature. Cancer Radiother. 2018;22(3):255-63. doi:10.1016/j.canrad.2017.10.006.

12. Semionov A, Khairo M. Mediastinal epithelioid hemangioendothelioma -Mimicker of mature teratoma. Radiol Case Rep. 2019;14(11):1420-2. doi:10.1016/j.radcr.2019.09.014.

13. Williams D, Zhou F, Grovenburg M, et al. Mediastinal cystic teratoma masquerading as a hydatid cyst. BMJ Case Rep. 2020 Jun 29;13(6):e234755. doi: 10.1136/bcr-2020-234755.

14. Matsuoka $\mathrm{H}$, Matsubara $\mathrm{H}$, Sugimura A, et al. Mediastinal mature teratoma perforating the right lung that was successfully resected with complete thoracoscopic surgery: A case report. Int J Surg Case Rep. 
2018;53:299-302. doi:10.1016/j.ijscr.2018.10.076.

15. Xiao-Dong L, Li Z, Xiu-Mei D, et al. Identification of a giant mediastinal teratoma by echocardiography: A case report. J Clin Ultrasound. 2019 Jul;47(6):380-3. doi:10.1002/jcu.22686.

16. Stajevic M, Dizdarevic I, Krunic I, et al. Mediastinal teratoma presenting with respiratory distress and cardiogenic shock in a neonate. Interact Cardiovasc Thorac Surg. 2020 May 1;30(5):788-789. doi: 10.1093/icvts/ivz328.

17. Kato H, Fukushima T, Kobayashi T, et al. [Mediastinal Growing Teratoma Syndrome during Chemotherapy, Presenting as a Huge and Inoperable Tumor]. Gan To Kagaku Ryoho. 2020;47(10):1497-500.

18. Al Smady M, Zahari NNB, Mohd Sahid NSB,et al. Anterior mediastinal teratoma with pericardial effusion. Rare presentation. J Surg Case Rep. 2019 May 9;2019(5):rjz136. doi: 10.1093/jscr/rjz136.

19. Liu J, Tian B, Zeng Q, et al. Mediastinal teratoma presenting with hemoptysis and pleuritis misdiagnosed as tuberculosis (empyema). BMC Pediatr. 2018 Dec;4(1):382. doi:10.1186/s12887-018-1357-7. 18 ) .

20. Mustafa OM, Mohammed SF, Aljubran A, et al. Immature mediastinal teratoma with unusual histopathology: A case report of multi-lineage, somatic-type malignant transformation and a review of the literature. Medicine (Baltimore). 2016 Jun;95(26):e3378. doi:10.1097/MD.0000000000003378.

21. Sachdeva AK, Penumadu P, Kohli $P$, et al. Growing teratoma syndrome in primary mediastinal germ cell tumor: our experience. Asian Cardiovasc Thorac Ann. 2019 Feb;27(2):98-104. doi:10.1177/0218492318823345.

22. Morikawa K, Tatsuno S, Misumi S. Rapid growth of a mature mediastinal teratoma in a middle-aged woman: A case report. Radiol Case Rep. 2020;15(10):1870-4. doi:10.1016/j.radcr.2020.07.054.

23. Agarwal A, Rosenkranz E, Yasin S, et al. EXIT procedure for fetal mediastinal teratoma with large pericardial effusion: a case report with review of literature. J Matern Fetal Neonatal Med. 2018 Apr;31(8):1099-103. doi:10.1080/14767058.2017.1306851.

24. Darouich S, Bellamine H. Fetal mediastinal teratoma: Misinterpretation as congenital cystic lesions of the lung on prenatal ultrasound. J Clin Ultrasound. 2020;48(5):287-90. doi:10.1002/jcu.22808.

\section{Figures}



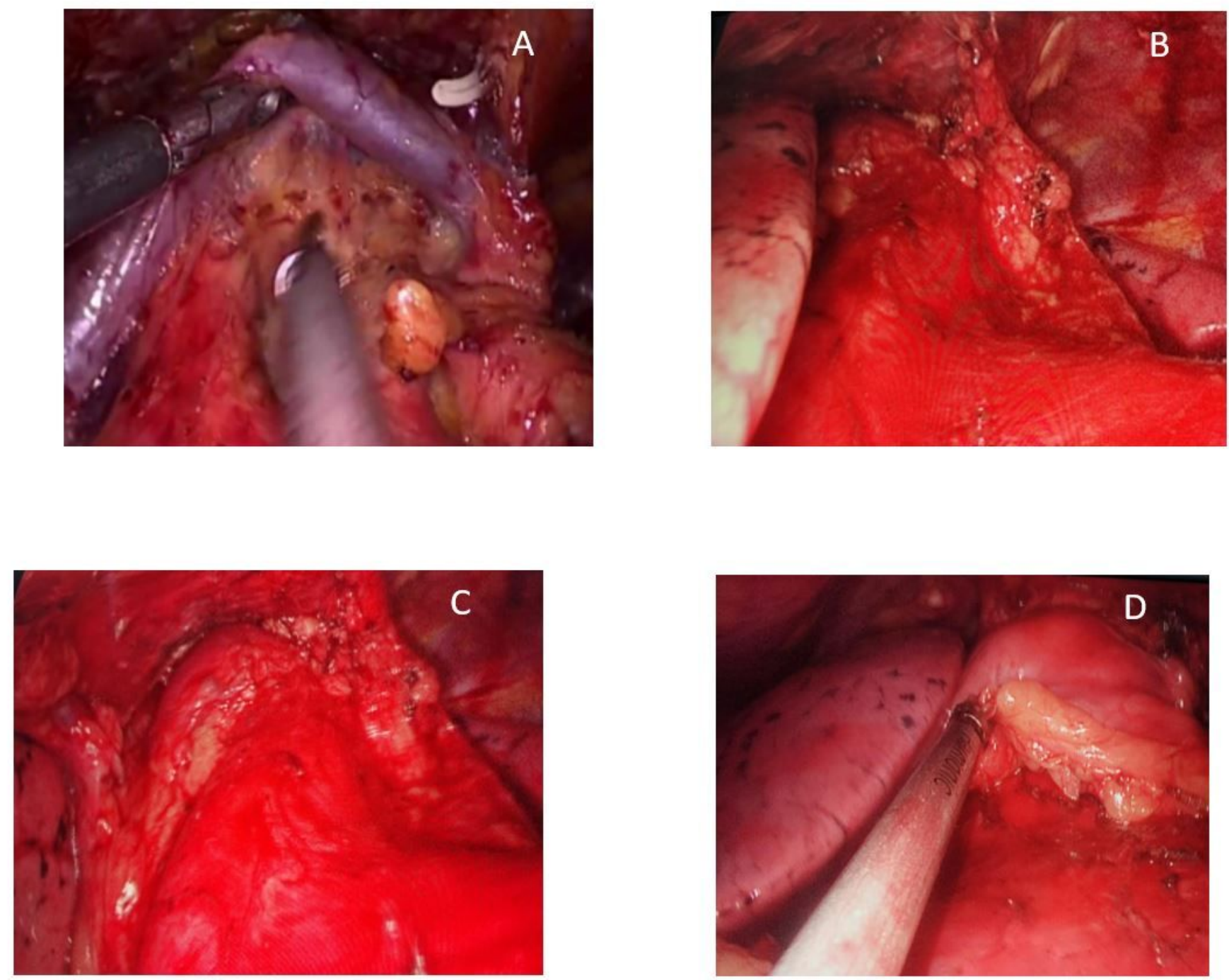

Figure 1

Operative Procedure (A-D) 